Research Article

\title{
Prefabricated Concrete Component Geometry Deviation Statistical Analysis
}

\author{
Xiaoyong Luo $\mathbb{D},,^{1,2}$ Hao Long $\mathbb{D},,^{1,2}$ Shuang Dong $\mathbb{D}^{1},{ }^{1}$ and Jingyi $W u \mathbb{C}^{3}$ \\ ${ }^{1}$ Department of Civil Engineering, Central South University, Changsha 41000, China \\ ${ }^{2}$ Hunan Prefabricated Construction Engineering Technology Research Centre, Changsha 41000, China \\ ${ }^{3}$ Hatchip Co., Shenzhen 518000, China \\ Correspondence should be addressed to Hao Long; longhao@csu.edu.cn
}

Received 22 March 2021; Revised 26 April 2021; Accepted 5 May 2021; Published 19 May 2021

Academic Editor: Jie Chen

Copyright (c) 2021 Xiaoyong Luo et al. This is an open access article distributed under the Creative Commons Attribution License, which permits unrestricted use, distribution, and reproduction in any medium, provided the original work is properly cited.

\begin{abstract}
The research objects of this paper were the prefabricated concrete components produced by four enterprises in China, and the dimension deviation data of more than 1400 prefabricated concrete components are measured with high-precision $3 \mathrm{D}$ photogrammetry technology. The nonparametric Kruskal-Wallis test was carried out for the size deviation of the same type of components produced by different enterprises. The distribution characteristics of geometric parameters of typical components of prefabricated structures in China, such as beams, columns, wall boards, and composite slabs, were analyzed by using the probability statistical method. The Kolmogorov-Smirnov goodness-of-fit method was used to test the cumulative distribution function of dimension deviation, and the size distribution of fabricated components was studied. The results showed that there was no significant difference in the size deviation of the same-type component produced by different enterprises, and the range of geometric parameter uncertainty random variables was small, which was between 0.99 and 1.02 . Also, the fluctuation was small, the coefficient of variation was below 0.0093 , and the variability of component size deviation was small. The transverse dimension of the component shows a positive deviation, the vertical dimension of component shows a negative deviation, and the dimension deviation of prefabricated concrete components follows the normal distribution.
\end{abstract}

\section{Introduction}

Prefabricated building is one of the important directions of building structure development, which is conducive to the development of building industrialization. As a crucial part of the prefabricated concrete (PC) structure, the quality of prefabricated components plays an important role in the overall structural performance [1]. In terms of the splicing structure of prefabricated components, if the size of prefabricated components is too large, it would be difficult to assemble and if the size is too small, the joints between components would be too large, causing water seepage problems. From the aspect of stress performance, when analyzing the reliability of the structure according to the probability limit state design method, the failure probability of the structural part or its corresponding reliability index is used as the measurement, and the geometrical dimension variable is one of the aspects that affect the resistance of the structural part. Moreover, contemporary buildings have become lighter and more vulnerable to building movement and subsequent geometric changes [2]. The lack of uniformity of accuracy between factory-made and in-situ components and the higher level of building movements in the contemporary building are two major factors that affect the dimensional and geometric accuracy of buildings [3]. The conversion of a good design into a good product (e.g., a building) is a matter of keeping dimensional and geometric variations within tolerances that are predetermined at the design stage [4]. The acceptability of a product depends on whether its variations in size and geometry fall within set limits; thus, the bridge between design and production is tolerance. In other words, tolerances interlink design with construction because without specifying the tolerances, it is not clear whether components and subassemblies (i.e., 
connections of two or more components) meet the design intent regarding the accuracy of the final product [5].

At present, there are many quality control standards for fabricated components, such as German DIN18203 and DIN18202 standards, Japanese JASS10, American MNL-116 and ACI regulations, and Chinese standards GB/T512312016 and GB/T 51232-2016 [6-10]. Each standard specifies the dimensional deviation of prefabricated components. These standards usually determine the allowable value of dimensional deviation based on traditional experiences [11], and the deviation allowable value for prefabricated components is strictly controlled and appropriately modified based on the relevant specifications of cast-in-place concrete. Scholars do not pay attention to the prefabricated component manufacturers' production capacity and have not systematically investigated the dimensional deviation of prefabricated components [12]. To determine the reliability of the concrete structure design, in the 1970s and 1980s [13], a survey of the size deviation of cast-in-place concrete structures was conducted in China [13]. Liu et al. [11] conducted the statistical investigation on the size deviation of cast-in-place concrete structures in Beijing and suggested adjusting the size deviation acceptance index, while Mao and Shi [14] conducted the statistical investigation and analysis on the section size and axis position of cast-in-place concrete structures, and they believed that the deviation of concrete section size obeys the normal distribution, yet the axis position deviation obeys the logarithmic distribution. Nowadays, there are many types of research on the size deviation of cast-in-situ structures, but there are quite few statistical studies on the size deviation of prefabricated concrete components. Therefore, it is of great significance to systematically investigate the size deviation of fabricated components.

In this paper, the dimensions of fabricated concrete components of different companies in China are measured by $3 \mathrm{D}$ photogrammetry technology, obtaining a database of wall board, composite slab, beam, and column size deviation. The dimensional deviation distribution characteristics of fabricated components are analyzed.

\section{Data Acquisition}

2.1. Overview of Sample Acquisition. The focus is mainly on the component forms existing in prefabricated building structures: beams, columns, wall panels, and composite slabs. In terms of survey objects, components produced by prefabricated component factories in different regions of China are mainly selected. Random sampling is used for each type of component. Detailed information about the number of survey samples is shown in Table 1 .

2.2. Measurement Method. Prefabricated building production and installation have higher precision requirements than traditional cast-in-situ concrete structures. The traditional measurement method for prefabricated concrete buildings is mainly using steel rulers, and there are problems with the use of steel rulers in measuring the dimensions of prefabricated concrete components, such as insufficient accuracy, large errors, and difficulty in measuring the edge corners of the component dimensions. The HL-3DP is a medium-range photogrammetry scanner type. It was designed for medium-space applications such as building, civil and survey, and forensics. Three-dimensional photogrammetry known as HL-3DP was applied for prefabricated concrete, and the scanned data were managed with their associated software HOLON3DP. HL-3DP is a high-accuracy and medium-range photogrammetry system. It is associated with a high-resolution camera. Table 2 shows the specification of HL-3DP. Therefore, in this article, HL-3DP three-dimensional photogrammetry was adopted to collect sample data. Figure 1 shows the on-site measurement of prefabricated components. The relative error of this method is less than $5 \%$, and the absolute error is less than $0.01 \mathrm{~mm}$. The measurement of the size of the prefabricated component, thus, resulted in high precision in terms of both experimental error and measurement accuracy.

2.3. Accuracy Assessment. Accuracy assessment was also performed in this study. The findings show that the $3 \mathrm{D}$ photogrammetry of HL-3DP can provide high accuracy of the building structure. To get a systematic accuracy assessment, the evaluation of the estimate accuracy was carried out using equation (1), where $x$ represents each value in the dataset, $\bar{x}$ represents the mean of all values in the dataset, and $n$ represents the number of value in the dataset.

$$
\mathrm{RMSE}=\sqrt{\frac{\sum_{i-1}^{n}(x-\bar{x})^{2}}{n}} .
$$

The root-mean-square error (RMSE) was used to measure the differences between values observed. According to Mao and Shi [14], RMSE is commonly used in the research field to describe the accuracy of features and it is acceptable to measure the error and estimate the quality of features. The lower the RMSE value, the better the accuracy.

Table 3 shows the dimensional measurement difference between the measuring steel tape and photogrammetry system. Meanwhile, the analysis for this study included the comparison of measurement between the photogrammetry system and conventional method (measuring steel tape) with the design value. The comparison is performed and recorded in Table 4. The RMSE value of the photogrammetry system data was $0.60 \mathrm{~mm}$ while that of the measuring steel tape method was $0.94 \mathrm{~mm}$. As the result, the tolerance of the photogrammetry system model is well within the 0.01 millimeter level. The photogrammetry system model has a lower tolerance compared to the measuring steel tap. This proved that the photogrammetry system method was accurate.

\section{Results of Sample Collection}

In the process of statistical analysis of the geometric parameters of the components, because the design dimensions of the components are not the same, to analyze and compare the variation of the dimensions described by the uncertainty 
TABLE 1: Sample number of prefabricated concrete members in different enterprises.

\begin{tabular}{lcccc}
\hline \multirow{2}{*}{ Survey object } & \multicolumn{2}{c}{ Sample number of prefabricated parts } \\
& Beam components & Column components & Wall panel components & Composite slab components \\
\hline Enterprise 1 & 62 & 66 & 102 & 87 \\
Enterprise 2 & 54 & 129 & 84 & 96 \\
Enterprise 3 & 76 & 94 & 64 & 111 \\
Enterprise 4 & 103 & 85 & 121 & 107 \\
\hline
\end{tabular}

TABLE 2: Specification of 3D photogrammetric HL-3DP.

HL-3DP 3D photogrammetric instrument

\begin{tabular}{l} 
Reasurement of noncontact optical tricoordinate \\
$\begin{array}{l}\text { Range measurement principle scanner control } \\
\text { Field of view }\end{array}$ \\
$\begin{array}{l}\text { Signal image } \\
\text { Ranging error }\end{array}$ \\
\hline
\end{tabular}

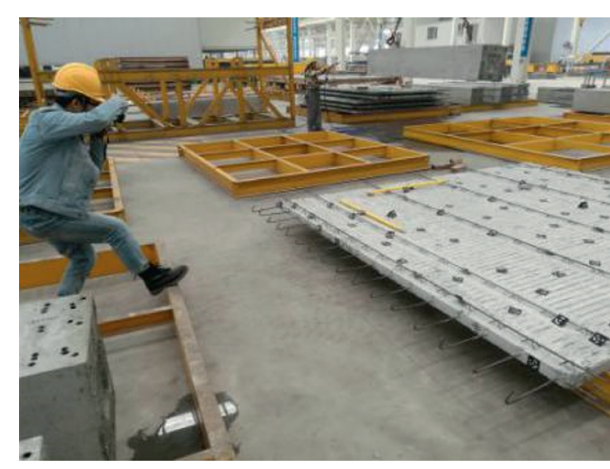

(a)



(b)

Figure 1: 3D photogrammetric component size. (a) Composite slab 3D measurement. (b) 3D measurement of prefabricated columns.

of the geometric parameters with the random variable $K_{A}$ [15], which can be expressed as shown in equation (2), where $a$ is the actual value of the geometric parameter of the component and $a_{K}$ is the standard value of the geometric parameter of the component (usually the design value),

$$
K_{A}=\frac{a}{a_{K}} \text {. }
$$

When analyzing the variability of the geometric dimensions of components, variables such as length, width, and height are regarded as independent random variables.
Taking the same type of component produced by the same enterprise as a matrix, its statistical parameters are analyzed with a subsample of capacity $n>50$. Integrating the statistical analysis results of various enterprises, the weighted average of the same type of component size variation is used to reflect the variation level of geometric dimensions. This paper is based on the measured data, and the number of subsamples participating in the statistical analysis is the weight (the capacity is $n$ ) [16]. Statistical parameters of random variables with uncertain geometric dimensions of various components were obtained as follows: 
TABLE 3: Result of dimensional measurement.

\begin{tabular}{lcccc}
\hline Prefabricated & Dimension & Design value $(\mathrm{mm})$ & Measuring steel tape $(\mathrm{mm})$ & Photogrammetry system $(\mathrm{mm})$ \\
\hline \multirow{3}{*}{ Prefabricated beam components } & Length & 2830 & 2833 & 2831.86 \\
& Width & 400 & 402 & 400.82 \\
& Height & 410 & 413 & 412.03 \\
\hline \multirow{3}{*}{ Prefabricated column components } & Length & 2535 & 2539 & 2537.08 \\
& Width & 500 & 503 & 502.07 \\
& Height & 520 & 523 & 520.67 \\
\hline \multirow{2}{*}{ Prefabricated wall panel components } & Weight & 6630 & 6633 & 6629.84 \\
& Width & 2600 & 2598 & 2599.24 \\
& Thickness & 240 & 238 & 240.65 \\
\hline \multirow{2}{*}{ Prefabricated composite slab* } & Length & 4350 & 4355 & 4346.06 \\
& Width & 3930 & 3933 & 3926.95 \\
\hline
\end{tabular}

* Since the thickness direction of the prefabricated composite slab is cast-in-place concrete, it was not counted.

TABLE 4: Comparison of measurement between the measuring steel tape and photogrammetry system.

\begin{tabular}{|c|c|c|c|c|}
\hline Prefabricated & Measuring steel tape $(\mathrm{mm})$ & $x^{2}$ & Photogrammetry system & $x^{2}$ \\
\hline Prefabricated & -3 & 9 & -1.86 & 3.46 \\
\hline \multirow{2}{*}{ Beam components } & -2 & 4 & -0.82 & 0.67 \\
\hline & -3 & 9 & -2.03 & 4.12 \\
\hline Prefabricated & -4 & 16 & -2.08 & 4.33 \\
\hline Column & -3 & 9 & -2.07 & 4.28 \\
\hline Components & -3 & 9 & -0.67 & 0.45 \\
\hline Prefabricated wall & -3 & 9 & 0.16 & 0.02 \\
\hline \multirow{2}{*}{ Panel components } & 2 & 4 & 0.76 & 0.58 \\
\hline & 2 & 4 & -0.65 & 0.42 \\
\hline Prefabricated & -5 & 25 & 3.94 & 15.52 \\
\hline Composite slab & -3 & 9 & 3.05 & 9.30 \\
\hline Sum & $\Sigma$ & 107 & $\Sigma$ & 43.15 \\
\hline RMSE & $\sqrt{\Sigma} / 11$ & 0.94 & $\sqrt{\Sigma} / 11$ & 0.60 \\
\hline
\end{tabular}

$$
\begin{aligned}
& \mu_{K_{A}}=\frac{\sum_{i=1}^{n} n_{i} \mu_{K_{A i}}}{\sum_{i=1}^{n} n_{i}}, \\
& \delta_{K_{A}}=\frac{\sum_{i=1}^{n} n_{i} \delta_{K_{A i}}}{\sum_{i=1}^{n} n_{i}},
\end{aligned}
$$

where $n_{i}$ is the subsample capacity of the geometric characteristic value of a certain construction unit, $\mu_{K_{A}}$ is the average value under capacity $n_{i}$, and $\delta_{K_{A}}$ is the coefficient of variation under $n_{i}$ capacity. According to equations (2) and (3), the statistical parameters of the random variable of the geometric parameters of the component can be obtained.

3.1. Analysis of Acquisition Results. Taking prefabricated concrete components produced by different companies as the research object, analyzing the difference in geometric uncertainty of component size in different enterprises, and calculating the average production component $K_{A}$ maximum, minimum, upper, and lower quartiles of each enterprise production, Figures $2-5$ give a comparison of box plots. The figures show the different production enterprise production ranges of similar artifacts are similar, both in the range of 0.99 to 1.02 . The abnormal port of beam members accounted for $3.4 \%$, the abnormal points of column members accounted for $0.8 \%$, the abnormal percentage of wall slabs accounts for $3.4 \%$, and the abnormal percentage of composite slab slabs accounts for $1.2 \%$. There are fewer abnormal points, which indicates that the variability of component size deviation in the actual production process is small. The volume of the box body represents the dense and discrete degree of data distribution in the group. The length and width of beams, columns, wall panels, slabs, and width values $K_{A}$ of the box body are relatively short, and the fluctuation is small.

Table 5 shows the comparison results of the $K_{A}$ value among similar components of different manufacturers. The horizontal size of the components produced by different enterprises (wall panel height, wall panel width, composite slab length, and composite slab width) dimension uncertainty is less than 1 , which is biased towards negative deviation, and longitudinal member dimensions are greater than 1 , which are biased toward positive deviation. The size deviation of similar PC components produced by different companies is not large, which proves the reliability of the measured data. Manufacturers have less influence on the size of prefabricated PC 


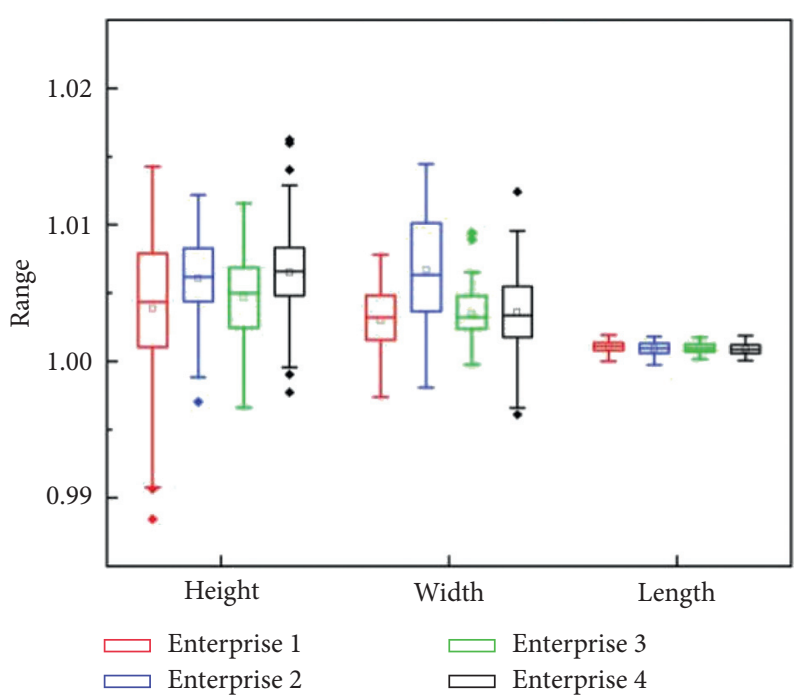

Figure 2: Box plot of geometric uncertainty of the beam member.

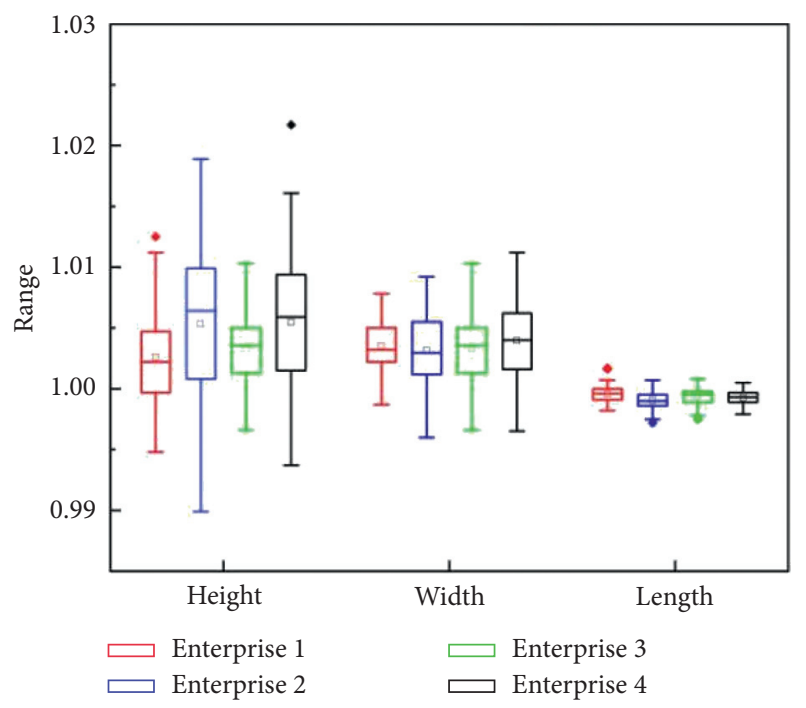

FIGURE 3: Box plot of geometric uncertainty of the column member.

components. The coefficients of variation $K_{A}$ are below 0.0093 , and the variation is small, indicating that similar components produced by different companies have the same size characteristics.

3.2. Correlation Test of Dimensional Deviation. With the significant level $a=0.05$ as the difference, a single factor analysis of variance on the dimensions of the components produced by the four companies is performed, the differences between the components produced by each factory are discussed, and it is evaluated whether the dimensional deviations of the components can be traced to a certain extent so that the measurement results of different component factories are comparable.

The Kruskal-Wallis test [17] infers whether the sample comes from the population median or the distribution pattern is significantly different. This method neither requires the data to obey the normal distribution nor does it require the homogeneity of variance. The Kruskal-Wallis test is a nonparametric test method to test whether multiple population distributions are the same. Firstly, samples in multiple groups are mixed and sorted in ascending order to find the rank of each variabl; if the values show no big difference, it can be considered that the distributions of multiple populations are not significantly different; on the contrary, if the rank means of each group are significantly different, the data of multiple groups cannot be mixed, and if the distributions of multiple samples are significantly different, the statistic constructed by the Kruskal-Wallis test is the $\mathrm{K}-\mathrm{W}$ statistic, which is $p \bar{R}_{i}, \bar{R}$, shown as follows:

$$
\begin{aligned}
p & =\frac{12}{N(N+1)} \sum_{i=1}^{k} n_{i}\left(\overline{R_{i}}-\bar{R}\right)^{2}, \\
\bar{R}_{i} & =\frac{R_{i}}{n_{i}} \\
\bar{R} & =\frac{N+1}{2},
\end{aligned}
$$

where $k$ is the number of sample groups, $N$ is the total sample size, $R_{i}$ is the sum of ranks of the group I, $\overline{R_{i}}$ is the average rank of the group I, and $\bar{R}$ is the total average rank.

Assuming that the distribution of the size deviation of similar components is the same in the company category, if $p<a$, the null hypothesis is rejected, and the size deviation distributions of similar components produced by different companies have significant differences; on the contrary, if $p>a$, then accept the null hypothesis, which means that the size deviation distribution of similar components produced by different companies has no significant difference. The nonparametric Kruskal-Wallis test was performed by SPSS19.0 software, and the analysis results are shown in Table 6. The significance value of each component size is greater than the significance level of 0.05 , accepting the former hypothesis, so there is no significant difference in the size deviation of similar components produced by different 


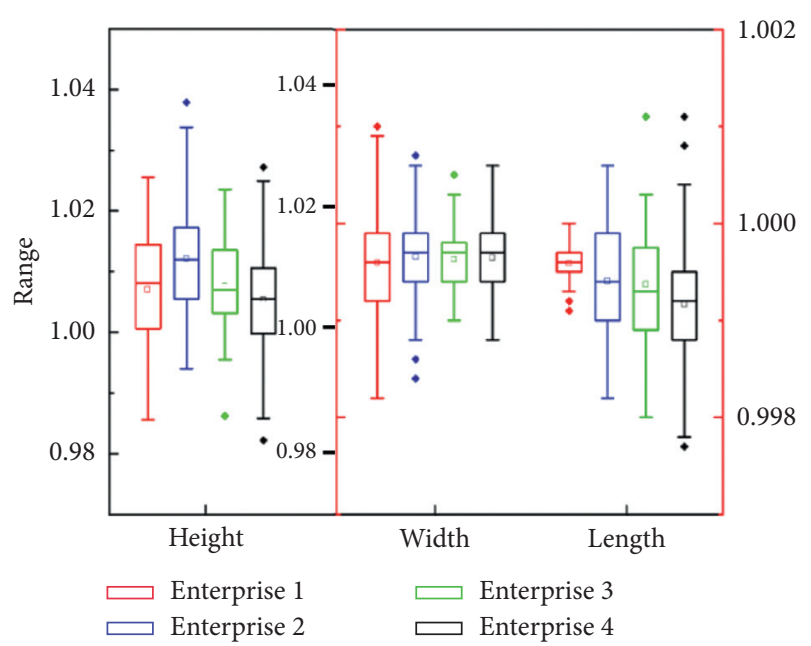

Figure 4: Box plot of wall panel geometric uncertainty.

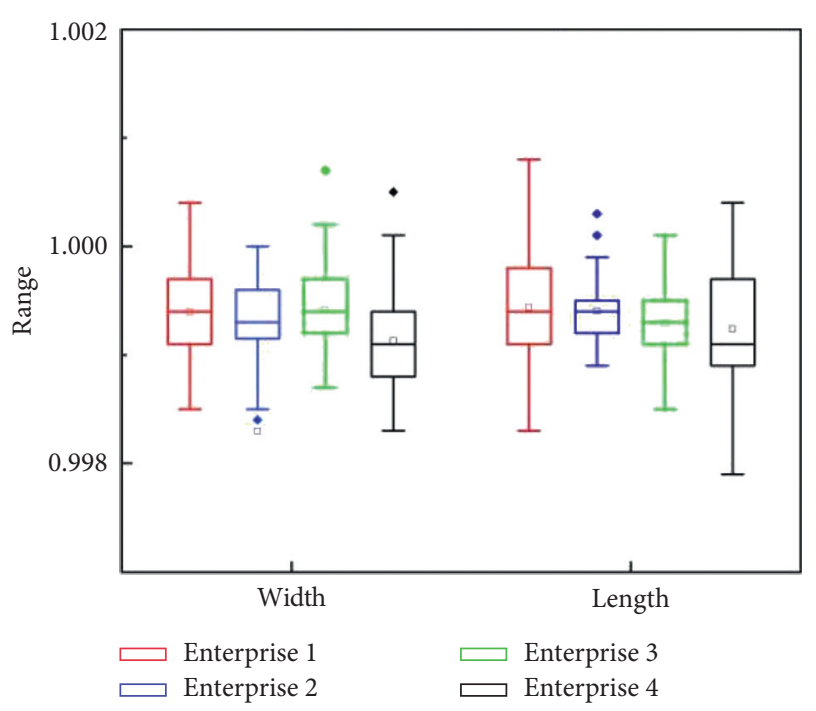

Figure 5: Box plot of geometric uncertainty of slab.

companies. The size deviation values of the same types of components produced by different companies can be used as subsamples to analyze the distribution characteristics of the size deviations of fabricated components in China.

\section{Frequency Distribution of Size Deviation}

Since there is no significant difference in the size deviation of the same type components, the size deviations of the sametype components produced by different companies are integrated as a sample of the size deviation, and the distribution law of size deviation is analyzed using histograms and box plots.

\subsection{Dimensional Deviation Distribution of Prefabricated} Beam Components. Calculating the difference between the measured data and the design value of the prefabricated beam, the sample size is 295 , which is divided into 20 groups. The histogram is drawn with the deviation value as the abscissa and the measured frequency as the ordinate, as shown in Figure 6.
As seen in Figure 6, the dimensional deviation distribution histogram for the beam decreases from the center to the sides, and it can be seen from Figure 6 that the dimensional deviation distribution histogram of the beam is a normal distribution.

The length deviation of beam components mainly concentrated in the range of $0-6 \mathrm{~mm}$, The most frequent deviation is $2-4 \mathrm{~mm}$, the mean is $3.02 \mathrm{~mm}$, and the variance is 1.91 . The width deviation range is mainly concentrated in the range of $0-3 \mathrm{~mm}$, the mean value is $1.57 \mathrm{~mm}$, and the variance is 1.56 , The height deviation is mainly concentrated in the range of $0-5 \mathrm{~mm}$, the mean value is $2.44 \mathrm{~mm}$, and the variance is 3.27 .

The maximum, minimum, upper quartile, lower quartile, and median of the size deviations are compared using box plots, as shown in Figure 7. The characteristic values of the three-dimensional dimensional deviation of prefabricated beam components are all significantly different, and the dimensional deviations are basically positive deviations. There is no abnormal value in the length dimension deviation, the median is located in the center of the upper and lower quartiles, and the box chart is symmetrical about the median line, indicating that the length dimension deviation is symmetrically distributed. Both height and width deviations have abnormal values. The height deviation abnormal values are concentrated on the smaller value side and the median tends to the upper quartile, indicating that the height size deviation distribution is right-skewed distribution. The width size deviation abnormal values are concentrated on the larger value side and the median tends to the lower quartile, indicating that the width deviation distribution is left-skewed distribution.

\subsection{Dimensional Deviation Distribution of Prefabricated} Column Components. Calculating the difference between the measured data and the design value of the prefabricated column, the sample size is 374 , which is divided into 20 groups. The histogram is drawn with the deviation value as the abscissa and the measured frequency as the ordinate, as shown in Figure 8. As seen in Figure 8, the dimensional deviation distribution histogram for the column decreases from the center to the sides, and it can be seen from Figure 8 that the dimensional deviation distribution histogram of the column is a normal distribution.

The length deviation of the column components mainly concentrated in the range of $-5-1 \mathrm{~mm}$, the most frequent deviation is $-3-1 \mathrm{~mm}$, the mean value is $-2.05 \mathrm{~mm}$, and the variance is 3.74 ; the width deviation mainly concentrated in the range of $-1-3.5 \mathrm{~mm}$, the most frequent deviation is $0.7-1.5 \mathrm{~mm}$, the mean value is $1.34 \mathrm{~mm}$, and the variance is 1.21 ; the height deviation is mainly concentrated in the range of $-2-5 \mathrm{~mm}$, the most frequent deviation is $1.5-2.5 \mathrm{~mm}$, the average is $1.88 \mathrm{~mm}$, and the variance is 4.34 .

The maximum, minimum, upper quartile, lower quartile, and median of the size deviations are compared using box plots, as shown in Figure 9. The characteristic values of the threedimensional dimensional deviation of prefabricated column components are all significantly different. There is no abnormal value for the width dimension deviation, the median deviation of width is located in the center of the upper and lower quartiles, 
TABLE 5: Summary of sample statistical.

\begin{tabular}{|c|c|c|c|c|c|c|c|c|c|}
\hline \multirow{2}{*}{$\begin{array}{l}\text { Prefabricated } \\
\text { components }\end{array}$} & \multirow{2}{*}{ Project } & \multicolumn{4}{|c|}{$\begin{array}{l}\mu_{k} / \mathrm{mm} \\
\left(\delta_{k}\right)\end{array}$} & \multicolumn{4}{|c|}{ Deviation range $(\mathrm{mm})$} \\
\hline & & $\begin{array}{c}\text { Enterprise } \\
1\end{array}$ & $\begin{array}{c}\text { Enterprise } \\
2\end{array}$ & Enterprise 3 & $\begin{array}{c}\text { Enterprise } \\
4\end{array}$ & Enterprise 1 & Enterprise 2 & Enterprise 3 & Enterprise 4 \\
\hline \multirow{3}{*}{$\begin{array}{l}\text { Prefabricated } \\
\text { beam member }\end{array}$} & Length & $\begin{array}{c}1.0011 \\
(0.0004)\end{array}$ & $\begin{array}{c}1.0009 \\
(0.0005)\end{array}$ & $\begin{array}{c}1.0010 \\
(0.0004)\end{array}$ & $\begin{array}{l}1.0065 \\
(0.0034)\end{array}$ & {$[0.04,5.44]$} & {$[-0.77,5.32]$} & {$[0.53,5.52]$} & {$[0.16,6.78]$} \\
\hline & Width & $\begin{array}{c}1.0030 \\
(0.0023)\end{array}$ & $\begin{array}{c}1.0067 \\
(0.0038)\end{array}$ & $\begin{array}{l}1.0035 \\
(0.0018)\end{array}$ & $\begin{array}{c}1.0036 \\
(0.0030)\end{array}$ & {$[-1.05,3.13]$} & {$[-0.81,6.06]$} & {$[-0.09,3.39]$} & {$[-1.48,4.72]$} \\
\hline & Height & $\begin{array}{c}1.0039 \\
(0.0056)\end{array}$ & $\begin{array}{c}1.0061 \\
(0.0032)\end{array}$ & $\begin{array}{c}1.0047 \\
(0.0031)\end{array}$ & $\begin{array}{c}1.0065 \\
(0.0034)\end{array}$ & {$[-4.74,5.85]$} & {$[-1.25,5.11]$} & {$[-1.56,5.33]$} & {$[-1.09,7.79]$} \\
\hline \multirow{3}{*}{$\begin{array}{l}\text { Prefabricated } \\
\text { column } \\
\text { member }\end{array}$} & Length & $\begin{array}{c}0.9996 \\
(0.0007)\end{array}$ & $\begin{array}{c}0.9991 \\
(0.0007)\end{array}$ & $\begin{array}{c}0.9993 \\
(0.0007)\end{array}$ & $\begin{array}{c}0.9993 \\
(0.0006)\end{array}$ & {$[-4.53,4.29]$} & {$[-8.06,1.81]$} & {$[-6.54,1.48]$} & {$[-6.16,1.09]$} \\
\hline & Width & $\begin{array}{c}1.0035 \\
(0.0019)\end{array}$ & $\begin{array}{c}1.0031 \\
(0.0029)\end{array}$ & $\begin{array}{c}1.0033 \\
(0.0029)\end{array}$ & $\begin{array}{c}1.0039 \\
(0.0032)\end{array}$ & {$[-0.25,3.91]$} & {$[-1.44,3.30]$} & {$[-1.30,3.90]$} & {$[-1.25,4.04]$} \\
\hline & Height & $\begin{array}{c}1.0026 \\
(0.0040)\end{array}$ & $\begin{array}{c}1.0053 \\
(0.0061)\end{array}$ & $\begin{array}{c}1.0033 \\
(0.0029)\end{array}$ & $\begin{array}{l}1.0055 \\
(0.0056)\end{array}$ & {$[-1.51,6.48]$} & {$[-3.65,6.21]$} & {$[-2.28,6.81]$} & {$[-2.19,8.23]$} \\
\hline \multirow{3}{*}{$\begin{array}{l}\text { Prefabricated } \\
\text { wall panel } \\
\text { components }\end{array}$} & Height & $\begin{array}{c}0.9996 \\
(0.0002)\end{array}$ & $\begin{array}{c}0.9994 \\
(0.0005)\end{array}$ & $\begin{array}{c}0.9994 \\
(0.0006)\end{array}$ & $\begin{array}{c}0.9992 \\
(0.0006)\end{array}$ & {$[-5.81,0.24]$} & {$[-5.42,2.16]$} & {$[-5.03,1.15]$} & {$[-6.57,3.29]$} \\
\hline & Width & $\begin{array}{c}0.9996 \\
(0.0005)\end{array}$ & $\begin{array}{c}0.9997 \\
(0.0004)\end{array}$ & $\begin{array}{c}0.9996 \\
(0.0003)\end{array}$ & $\begin{array}{c}0.9997 \\
(0.0004)\end{array}$ & {$[-4.75,2.29]$} & {$[-4.36,2.05]$} & {$[-3.32,1.77]$} & {$[-4.38,2.04]$} \\
\hline & Thickness & $\begin{array}{c}1.0071 \\
(0.0093) \\
\end{array}$ & $\begin{array}{c}1.0121 \\
(0.0089) \\
\end{array}$ & $\begin{array}{c}1.0076 \\
(0.0070) \\
\end{array}$ & $\begin{array}{c}1.0054 \\
(0.0084) \\
\end{array}$ & {$[-3.45,5.88]$} & {$[-0.67,5.98]$} & {$[-1.09,4.48]$} & {$[-4.28,5.98]$} \\
\hline \multirow{2}{*}{$\begin{array}{l}\text { Prefabricated } \\
\text { composite } \\
\text { slab }\end{array}$} & Length & $\begin{array}{c}0.9994 \\
(0.0006)\end{array}$ & $\begin{array}{c}0.9994 \\
(0.0003)\end{array}$ & $\begin{array}{c}0.9993 \\
(0.0003)\end{array}$ & $\begin{array}{c}0.9992 \\
(0.0005)\end{array}$ & {$[-5.99,3.10]$} & {$[-4.84,1.12]$} & {$[-5.23,0.23]$} & {$[-5.41,0.92]$} \\
\hline & Width & $\begin{array}{c}0.9994 \\
(0.0004)\end{array}$ & $\begin{array}{c}0.9993 \\
(0.0003)\end{array}$ & $\begin{array}{c}0.9994 \\
(0.0004)\end{array}$ & $\begin{array}{c}0.9991 \\
(0.0004)\end{array}$ & {$[-4.88,1.22]$} & {$[-6.20,0.09]$} & {$[-3.89,2.13]$} & {$[-3.48,1.10]$} \\
\hline
\end{tabular}

TABLE 6: Kruskal-Wallis inspection of component size deviation.

\begin{tabular}{|c|c|c|c|c|c|c|}
\hline Prefabricated components & Project & $N$ & $R_{i}$ & $\overline{R_{i}}$ & $p$ & $a^{*}$ \\
\hline \multirow{3}{*}{ Prefabricated beam member } & Length & 295 & 584.07 & 146.02 & 0.131 & \multirow{11}{*}{0.05} \\
\hline & Width & 295 & 611.65 & 152.91 & 0.177 & \\
\hline & Height & 295 & 575.88 & 143.97 & 0.123 & \\
\hline \multirow{3}{*}{ Prefabricated column member } & Length & 368 & 765.93 & 191.48 & 0.401 & \\
\hline & Width & 368 & 741.33 & 185.33 & 0.231 & \\
\hline & Height & 368 & 727.64 & 181.91 & 0.090 & \\
\hline \multirow{3}{*}{ Prefabricated wall panel components } & Height & 404 & 818.47 & 204.61 & 0.061 & \\
\hline & Width & 404 & 818.34 & 204.59 & 0.053 & \\
\hline & Thickness & 404 & 821.64 & 205.41 & 0.077 & \\
\hline \multirow{2}{*}{ Prefabricated composite slab } & Length & 401 & 808.91 & 202.23 & 0.097 & \\
\hline & Width & 401 & 796.64 & 199.16 & 0.081 & \\
\hline
\end{tabular}

*Significance is progressive significance, and the significance level is 0.05 .

and the square box chart is symmetrical about the median line, which means that the dimension deviation is symmetrically distributed. The abnormal values of height deviation are concentrated on the side of the larger value, and the median deviation tends to the upper quartile, indicating that the height dimension deviation is right-skewed distribution. Although there are outliers on both sides of the length deviation, the box chart is symmetrical about the median, and the proportion of the outliers in the upper and lower quartiles is consistent; therefore, it can be considered that the length deviation is symmetrical.

4.3. Dimensional Deviation Distribution of Prefabricated Wall Panel Components. Calculating the difference between the measured data and the design value of the prefabricated wall panel, the sample size is 371 , which is divided into 20 groups. The histogram is drawn with the deviation value as the abscissa and the measured frequency as the ordinate, as shown in Figure 10. As seen in Figure 10, the dimensional deviation distribution histogram for the wall panel decreases from the center to the sides, and it can be seen from Figure 10 that the dimensional deviation distribution histogram of the wall panel is a normal distribution.

The height deviation size of prefabricated wall panels is mainly concentrated in the range of $-5-0 \mathrm{~mm}$, the most frequent deviation is $-3.5-2.8 \mathrm{~mm}$, the average is $-2.39 \mathrm{~mm}$, and the variance is 2.91 . The width deviation mainly concentrated in the range of $-3-0.5 \mathrm{~mm}$, the most frequent deviation was -1$0.6 \mathrm{~mm}$, the mean value was $-1.13 \mathrm{~mm}$, and the variance was 1.57. The thickness deviation is mainly concentrated in the 




(a)

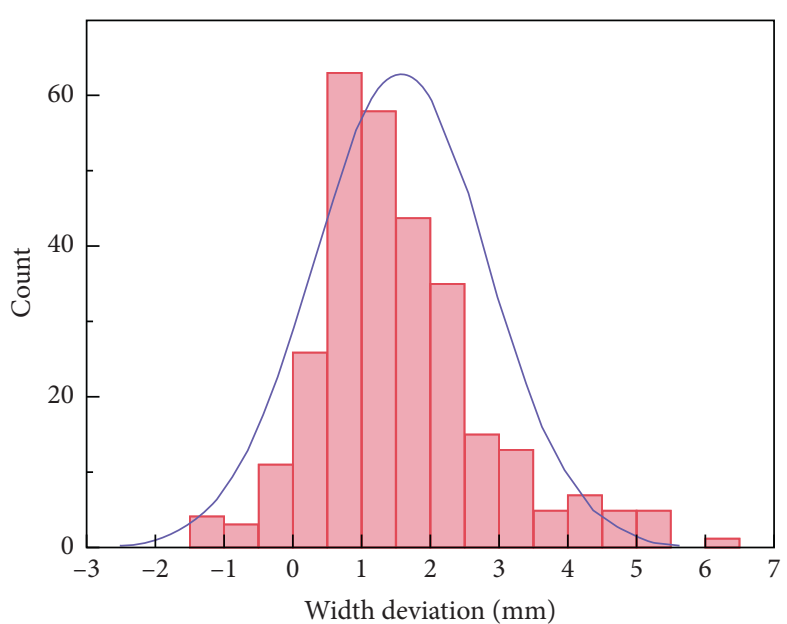

(b)



(c)

Figure 6: Histogram of beam member size deviation distribution. (a) Statistical histogram of beam length deviation. (b) Statistical histogram of beam width deviation. (c) Statistical histogram of beam height deviation.

range of $-1.5-4 \mathrm{~mm}$, the most frequent deviation is $1.0-1.6 \mathrm{~mm}$, the average is $1.81 \mathrm{~mm}$, and the variance is 4.13 .

The maximum, minimum, upper quartile, lower quartile, and median of the size deviations are compared using box plots, as shown in Figure 11. The characteristic values of the threedimensional dimensional deviation of prefabricated wall panel components are all significantly different. The characteristic values of the wallboard size deviation are significantly different. The height and width deviations are basically negative deviations, and the thickness deviations are basically positive deviations. The abnormal values of height and width deviations are concentrated on the larger value side, and the median deviation tends to the upper quartile indicating that the height dimension deviation and width dimension deviation are right-skewed distribution, and the thickness deviation abnormal values are concentrated on the smaller value side, which means that the thickness deviation distribution is left-skewed distribution.

4.4. Dimensional Deviation Distribution of Prefabricated Composite Slab Components. Because the thickness direction of the composite slab is cast-in-place concrete, the thickness of the composite slab is not counted. Calculating the difference between the measured data and the design value of the prefabricated composite slab components, the sample size is 401 , which is divided into 20 groups. The histogram is drawn with the deviation value as the abscissa and the measured frequency as the ordinate, as shown in Figure 12. As seen in Figure 12, the dimensional deviation distribution histogram for composite slab decreases from the center to the sides, and it can be seen from Figure 12 that the dimensional deviation distribution histogram of the composite slab is a normal distribution.

The length deviation size of the composite slab is mainly concentrated in the range of $-5-0 \mathrm{~mm}$, the most frequent deviation is $-2.6-2.0 \mathrm{~mm}$, the mean value is $-2.44 \mathrm{~mm}$, and the variance is 2.21 ; The width deviation mainly concentrated in the range of $0-3 \mathrm{~mm}$, the most frequent deviation is $-2.5-2.0 \mathrm{~mm}$, the mean value is $1.34 \mathrm{~mm}$, and the variance is 1.21 .

The maximum, minimum, upper quartile, lower quartile, and median of the size deviations are compared using box plots, as shown in Figure 13. The dimensional 


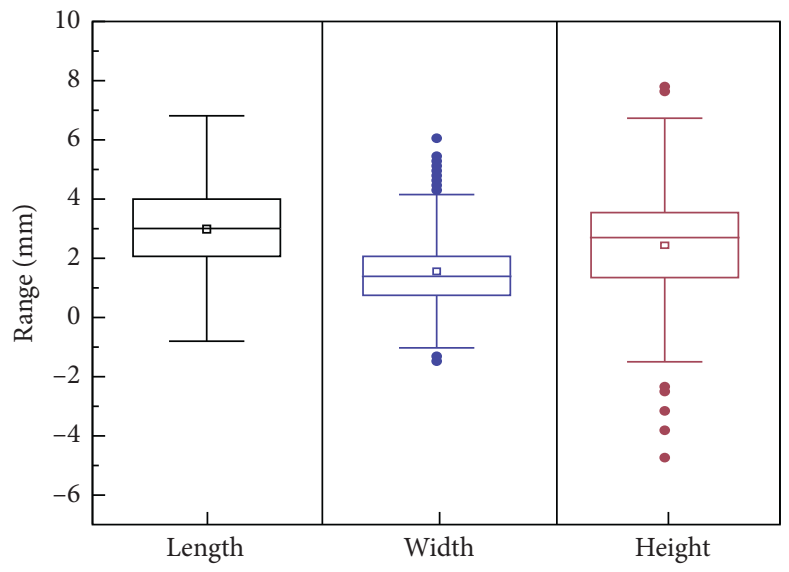

FIgURE 7: Box plot of beam size deviation distribution.

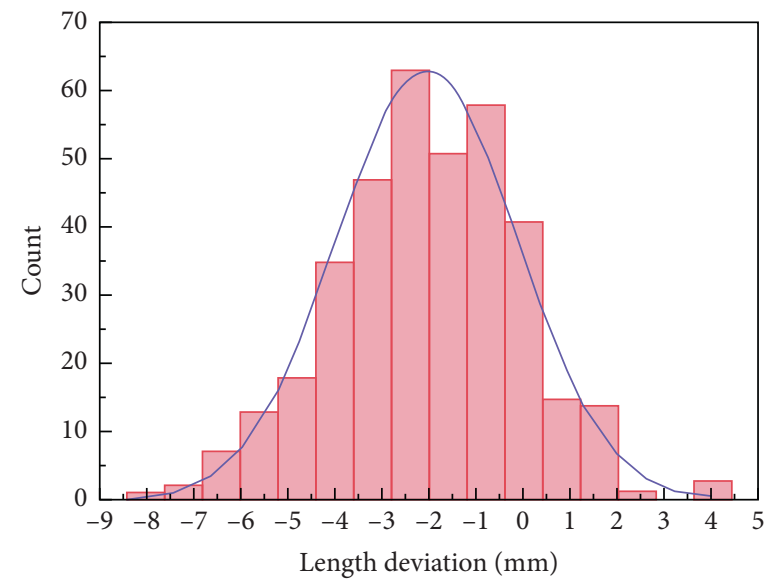

(a)

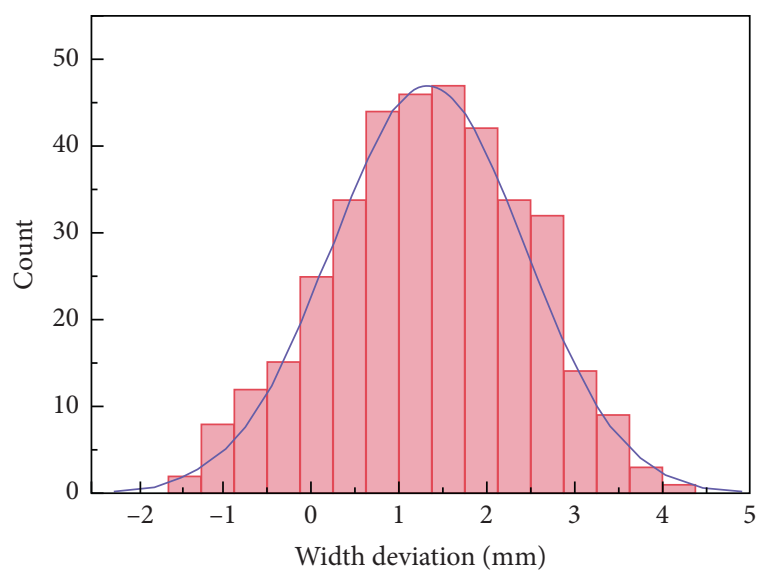

(b)

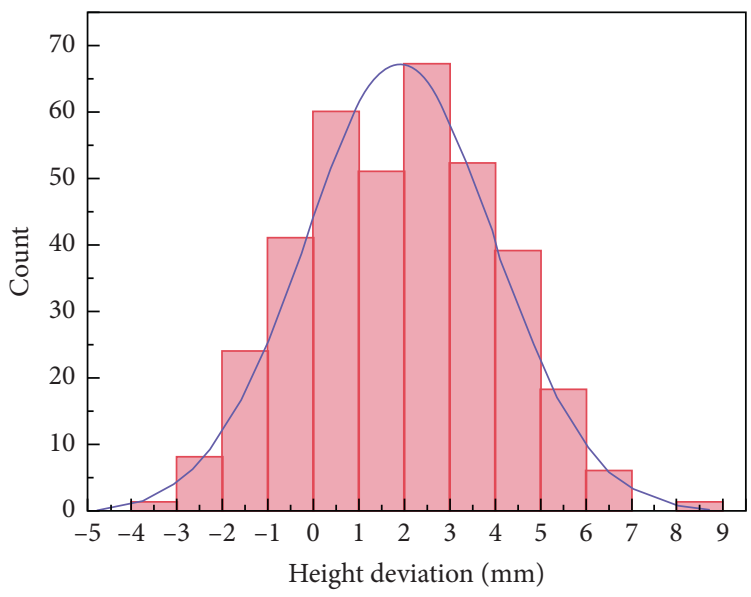

(c)

FIgURE 8: Histogram of column member size deviation distribution. (a) Statistical histogram of column length deviation. (b) Statistical histogram of column width deviation. (c) Statistical histogram of column height deviation.

deviation characteristic values of the composite slab slabs are all significantly different, and the dimensional deviations are basically negative deviations, there are abnormal values in the length and height deviation. The length deviation abnormal value is concentrated on the larger value side, which means that the length deviation distribution is skewed to the left-skewed distribution, and the width deviation abnormal values are concentrated on the side of the smaller value, which means that the width deviation distribution is right-skewed distribution. 


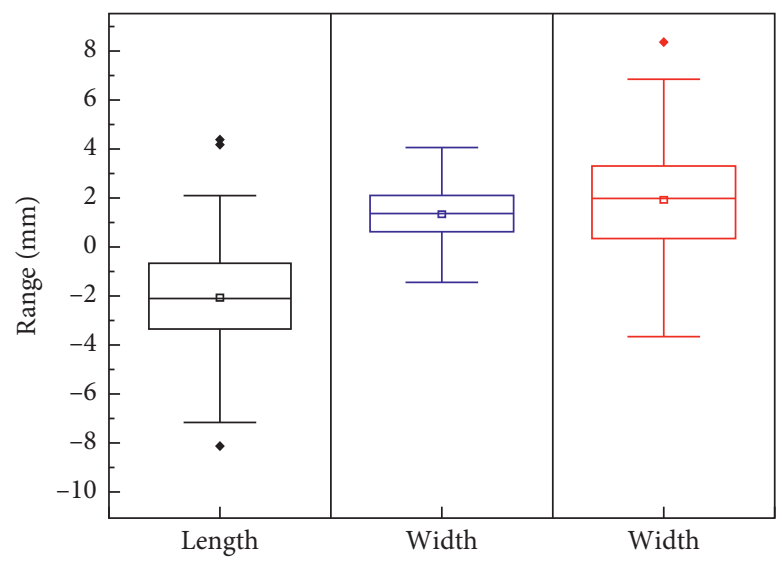

Figure 9: Box plot of column size deviation distribution.

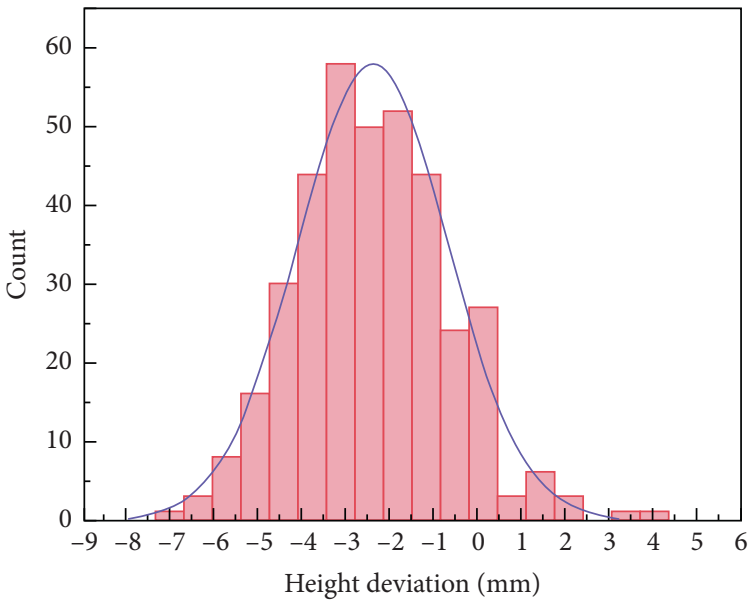

(a)

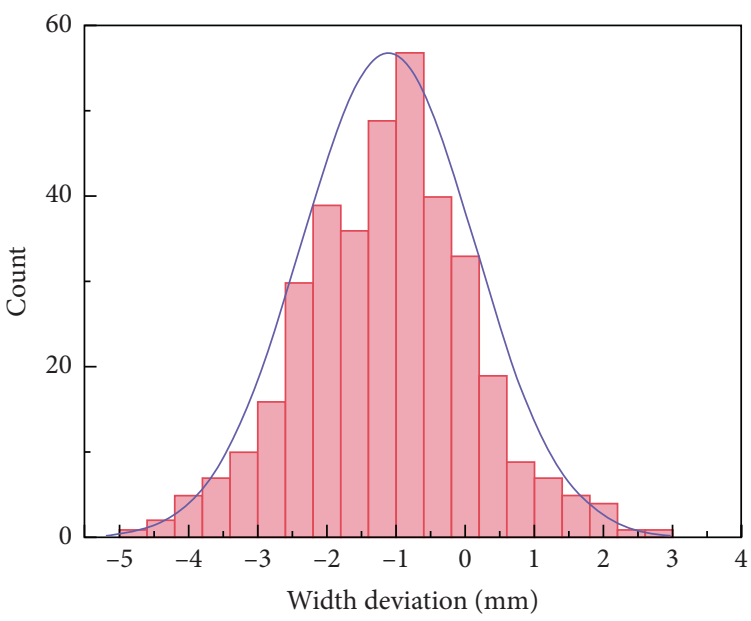

(b)

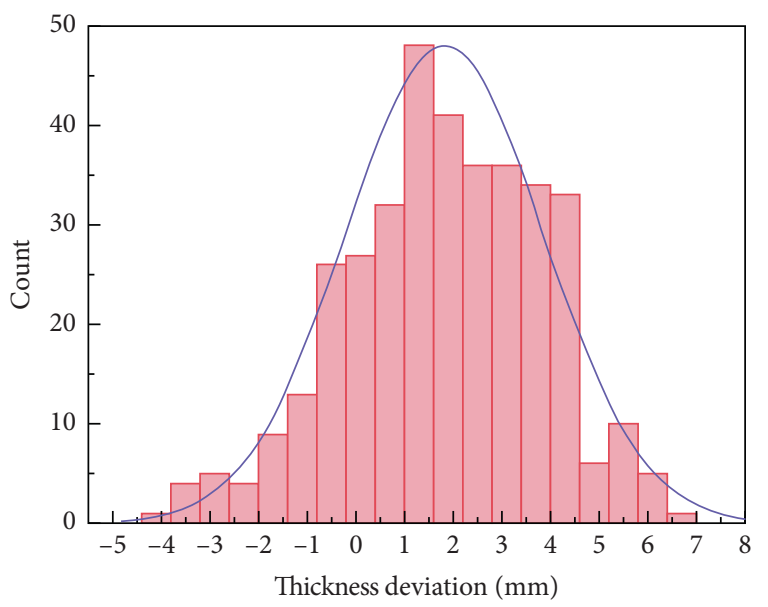

(c)

FIGURE 10: Histogram of wall panel size deviation. (a) Statistical histogram of wall panel height deviation. (b) Statistical histogram of wall panel width deviation. (c) Statistical histogram of wall panel thickness deviation.

4.5. Frequency Distribution Inspection of Dimensional Deviation. In statistics, the Kolmogorov-Smirnov test (KS test) $[18,19]$ is used to test whether two empirical distributions are the same or whether one empirical distribution is different from another ideal distribution. Assuming that $X_{1}, X_{2}, \ldots, X_{N}$ and $Y_{1}, Y_{2}, \ldots, Y_{N}$ are two 


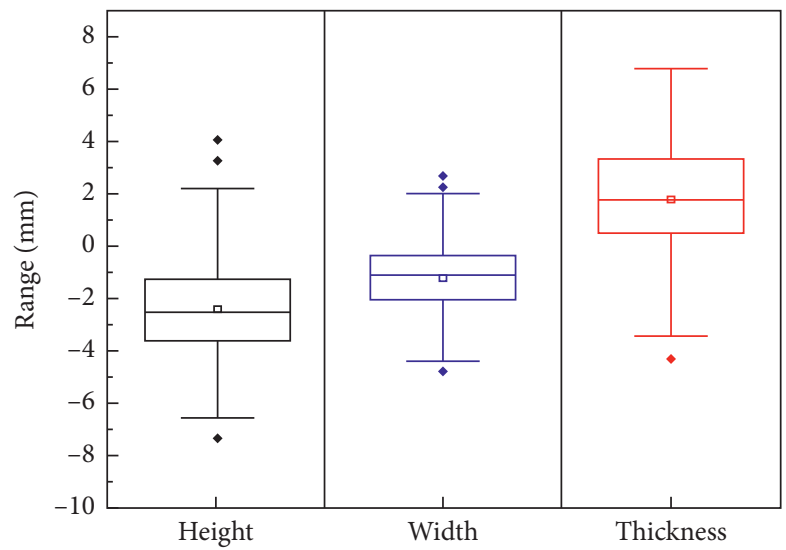

FIGURE 11: Box plot of wall panel size deviation distribution.

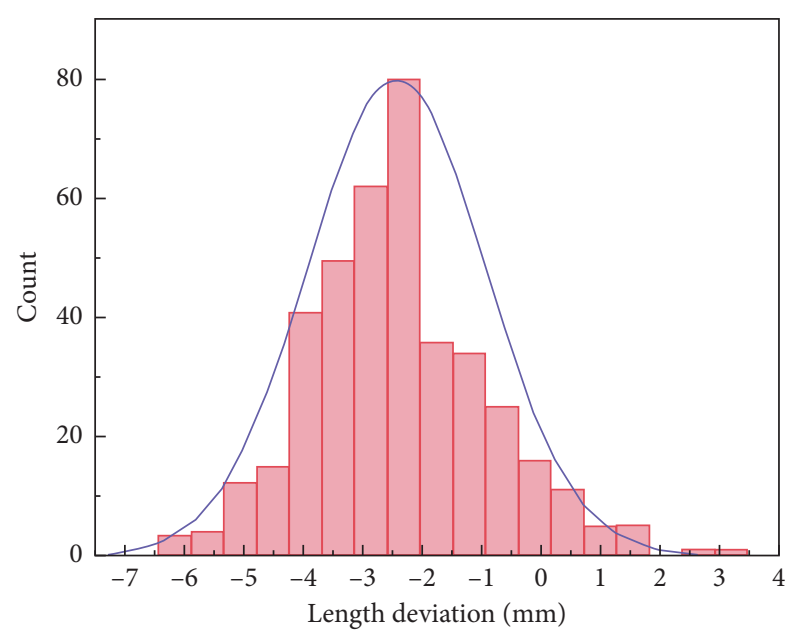

(a)

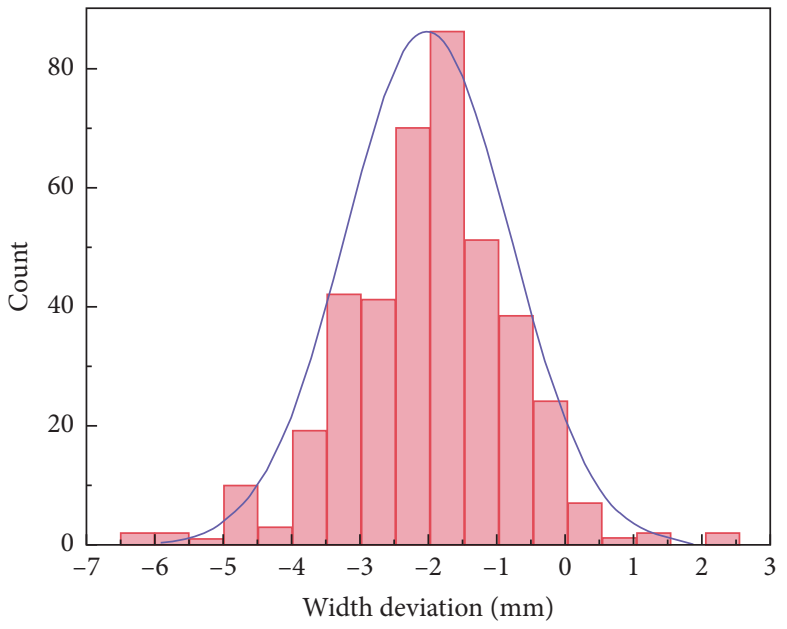

(b)

Figure 12: Histogram of composite slab size deviation distribution. (a) Statistical histogram of length deviation of composite slab. (b) Statistical histogram of width deviation of the composite slab.

different samples, $K-S$ can be used to test whether the two samples belong to the same population, and it depends on the value of the test statistic $D$. The $D$ value is defined as

$$
D=\max \left|S_{X}(x)-S_{Y}(x)\right|
$$

Among them, $S_{X}(x)$ and $S_{Y}(x)$ are the cumulative distribution functions of the two samples, respectively. If the value of $D$ is small, it can be judged that the two samples are from the same population. Taking into account that the versatility of the normal probability distribution to random variables and the general significance of Weibull's theory in analyzing the size effect of concrete [20], these two probability statistical distributions are compared with the size deviation values of fabricated components. By using Matlab, the normal distribution function $y=\operatorname{normrnd}(\bar{X}, \sigma, m, n)$ is used to generate a sample that conforms to the normal distribution with the average value $\bar{X}$ and the standard deviation $\sigma$. The Weibull distribution function $y=$ weibrnd $(\bar{X}, a, b)$ is used to generate a sample that conforms to the Weibull distribution with $\bar{X}$ as the average, where $a$ is the scale parameter and $b$ is the shape parameter.
Figures 14-17 are the curve fitting diagram of the cumulative distribution function of different component size deviations. The Weibull cumulative distribution function curve and the normal distribution function curve are similar to the component size deviation cumulative distribution function curve. Intuitively, the length deviation cumulative distribution and the width size deviation fit well with the normal distribution, but are significantly different with the Weibull distribution. In the deviation distribution of wallboard height and wallboard thickness, the Weibull cumulative distribution and the normal cumulative distribution function curve are in good agreement. To accurately compare and determine the best distribution, it is necessary to further calculate the maximum absolute deviation among the theoretical distribution function, the empirical distribution function, and the probability $P$ of making the first type of error. The specific results are shown in Table 4 . Among them, $D$ is calculated according to equation (6), and the value of $P$ is calculated under the hypothesis of the Kolmogorov distribution of the limit distribution of $D$.

The KS test results of size deviation frequency, normal distribution, and Weibull distribution are shown in Table 7. 


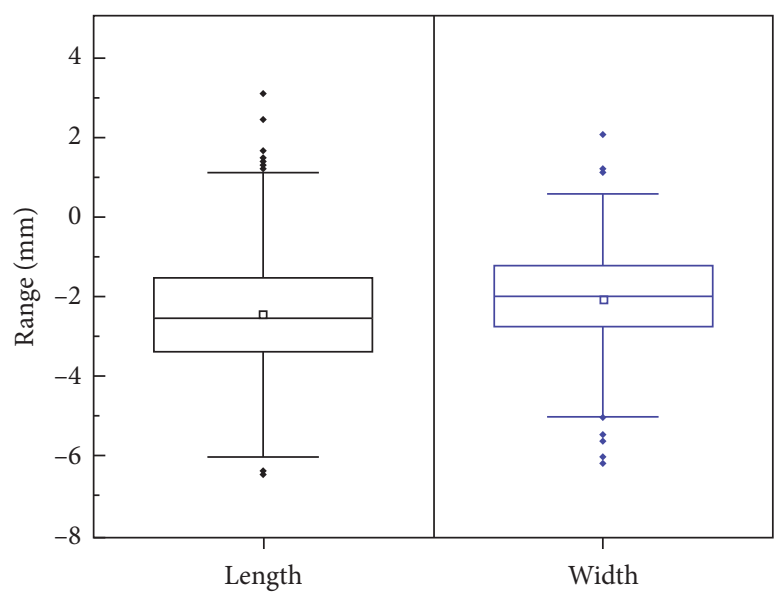

FIgURE 13: Box plot of composite slab size deviation distribution.

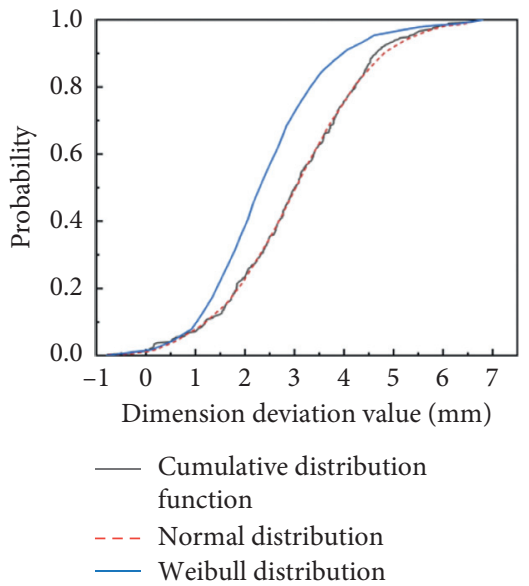

(a)

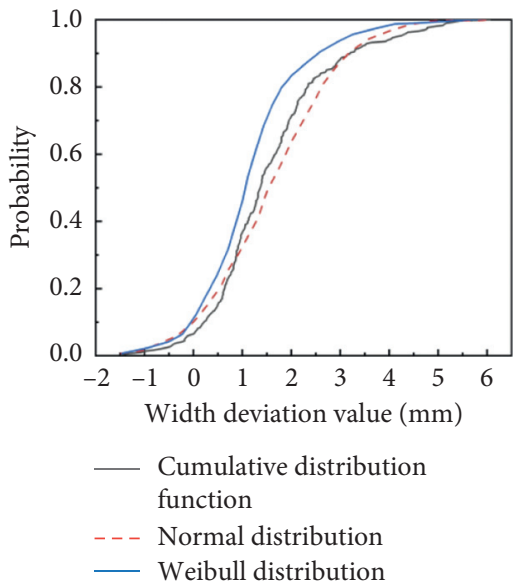

(b)

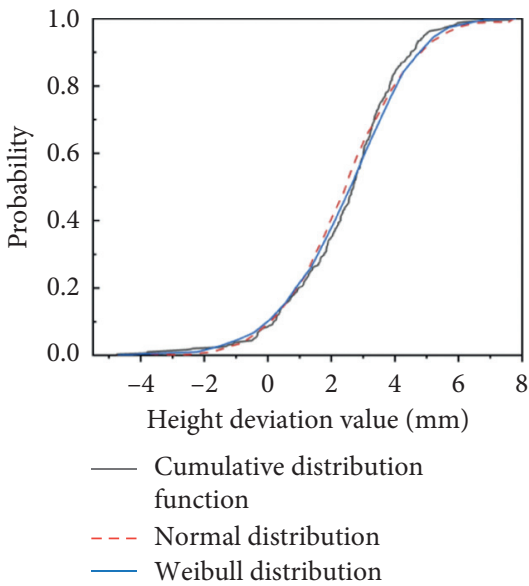

(c)

Figure 14: The cumulative distribution function of beam size deviation. (a) The cumulative distribution function of beam length deviation. (b) The cumulative distribution function of beam width deviation. (c) The cumulative distribution function of beam height deviation.

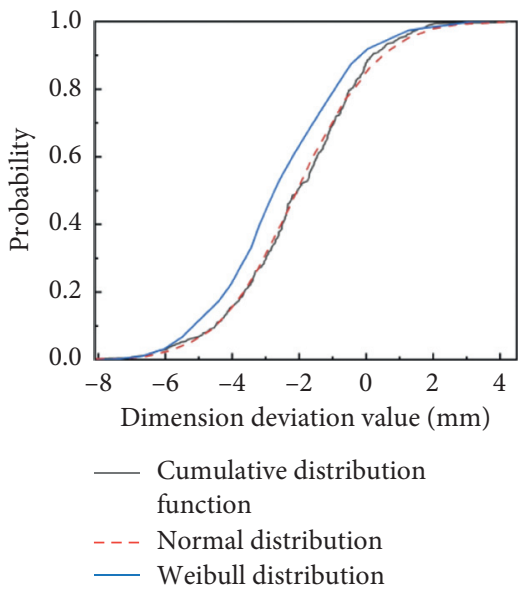

(a)

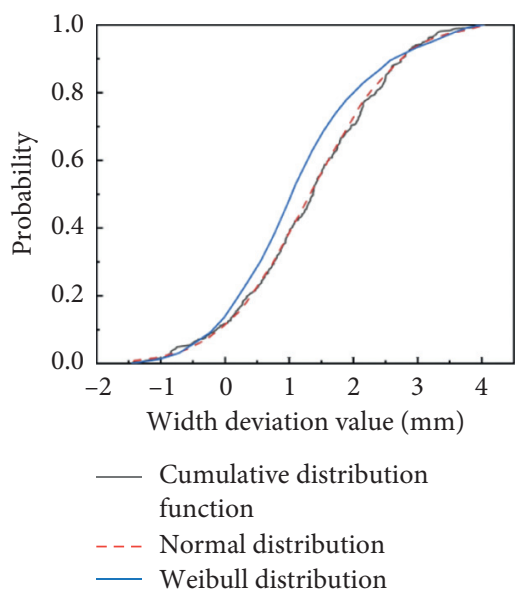

(b)

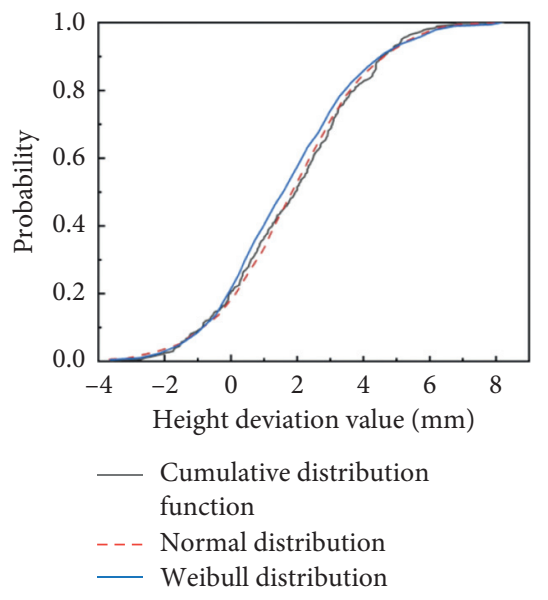

(c)

Figure 15: The cumulative distribution function of column size deviation. (a) The cumulative distribution function of column length deviation. (b) The cumulative distribution function of column width deviation. (c) The cumulative distribution function of column height deviation. 


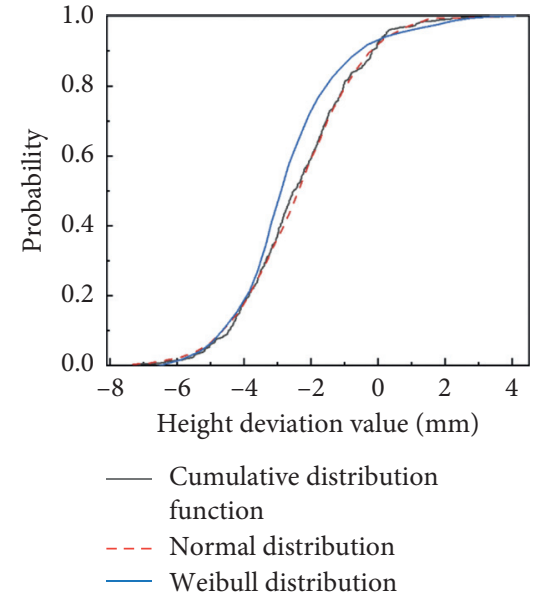

(a)

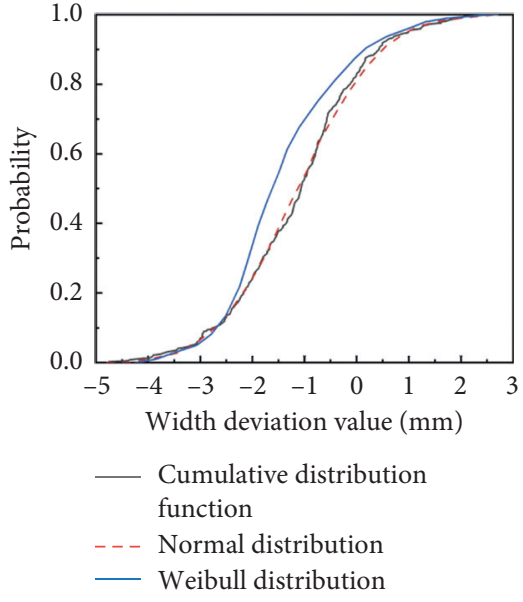

(b)

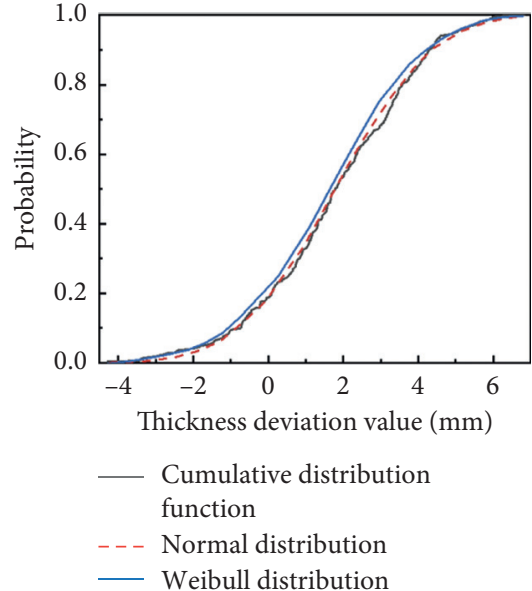

(c)

FIGURE 16: The cumulative distribution function of sample value of wall panel size deviation. (a) The cumulative distribution function of wall panel height deviation. (b) The cumulative distribution function of wall panel width deviation. (c) The cumulative distribution function of wall panel thickness deviation.

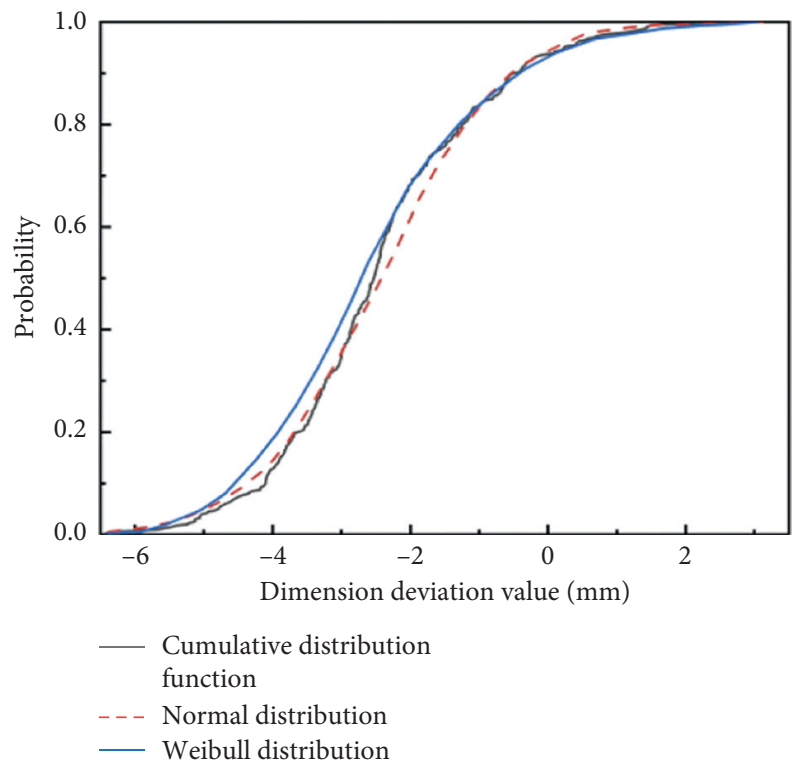

(a)

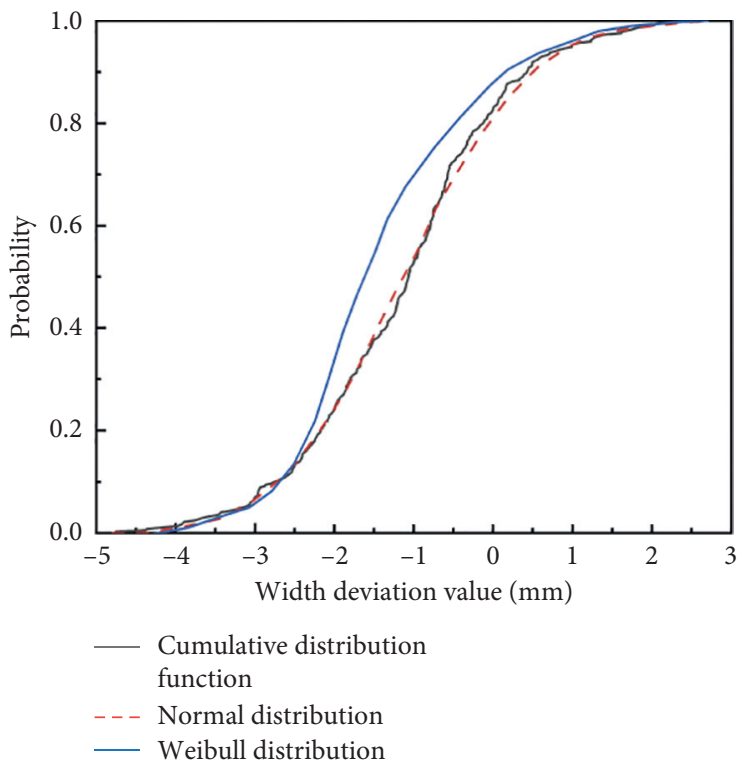

(b)

FIGURE 17: The cumulative distribution function of sample value deviation of superimposed slab size. (a) The cumulative distribution function of length deviation of composite. (b) The cumulative distribution function of height deviation of composite slab.

It can be seen from Table 7 that, in the two distributions, the maximum absolute value of the normal distribution $D$ is the smallest, and the $P$ value of the normal distribution is the smallest. If the significance is taken at the level of 0.05 , the fitting effects of normal distribution and Weibull distribution are both acceptable, and it is obvious that the former is 
TABLE 7: KS inspection result of size deviation.

\begin{tabular}{|c|c|c|c|c|c|}
\hline \multirow{2}{*}{ Prefabricated components } & \multirow{2}{*}{ Project } & \multicolumn{2}{|c|}{ Normal distribution } & \multicolumn{2}{|c|}{ Weibull distribution } \\
\hline & & $D$ & $P$ & $D$ & $P$ \\
\hline \multirow{3}{*}{ Prefabricated beam member } & Length & 0.038 & 0.592 & 0.213 & 0.039 \\
\hline & Width & 0.177 & 0.187 & 0.098 & 0.028 \\
\hline & Height & 0.044 & 0.331 & 0.052 & 0.311 \\
\hline \multirow{3}{*}{ Prefabricated column member } & Length & 0.073 & 0.429 & 0.189 & 0.033 \\
\hline & Width & 0.098 & 0.373 & 0.167 & 0.048 \\
\hline & Height & 0.031 & 0.333 & 0.094 & 0.309 \\
\hline \multirow{3}{*}{ Prefabricated wall panel components } & Height & 0.055 & 0.419 & 0.193 & 0.037 \\
\hline & Width & 0.061 & 0.380 & 0.313 & 0.018 \\
\hline & Thickness & 0.035 & 0.377 & 0.051 & 0.293 \\
\hline \multirow{2}{*}{ Prefabricated composite slab* } & Length & 0.087 & 0.199 & 0.199 & 0.038 \\
\hline & Width & 0.019 & 0.211 & 0.227 & 0.031 \\
\hline
\end{tabular}

* Since the thickness direction of the prefabricated composite slab is cast-in-place concrete, it was not counted.

better. It shows that the dimensional deviation of fabricated components conforms to the null hypothesis and normal distribution.

\section{Conclusions}

In this paper, three-dimensional surveys of more than 1,400 prefabricated components in China were carried out, and the geometric parameters of the components were statistically analyzed using probability and statistics methods, hence obtaining the following conclusions:

(1) The range of the geometric parameter uncertainty random variable of the same component size produced by different enterprises shows little difference and the fluctuation is small, ranging from 0.99 to 1.02. The geometric parameter uncertainty coefficient of variation is below 0.0093 , and the component size deviation variability is small.

(2) The significance of the correlation degree of the prefabricated component size deviation is greater than the level of 0.05 , and there is no significant difference among the size deviations of similar components produced by different companies.

(3) The histogram of the frequency distribution of prefabricated component size deviation decreases from the center to both sides, and the fitting curve has only one peak. The geometric uncertainties of the transverse dimensions of the components are all less than 1 , which tend to be negative deviations, and the geometric uncertainties of the longitudinal dimensions are all greater than 1 , which tend to be positive deviations.

(4) The size deviation of fabricated components does not refuse to obey the normal distribution and the Weibull distribution, but it is more inclined to obey the normal distribution.

\section{Data Availability}

The [xls] data used to support the findings of this study are available from the corresponding author upon request.

\section{Conflicts of Interest}

The authors declare that they have no conflicts of interest.

\section{Acknowledgments}

The authors gratefully acknowledge the financial support for this research by the applied basic research program of China's 13th Five-Year Plan (2016YFC0701705-1).

\section{References}

[1] T. Song, Study on quality control of prefabricated concrete structure, Ph.D. dissertation, Xi'an University of Architecture and Technology, Xian, China, 2017.

[2] C. T. Milberg and I. D. Tommelein, "Methods for managing tolerance compatibility:Windows in cast-in-place concrete," Journal of Construction Engineering and Management, vol. 146, no. 2, Article ID 04019105, 2020.

[3] S. Talebi, "Improvement of dimensional tolerance management in construction," Ph.D. dissertation, University of Hudderfield, Huddersfield, WY, UK, 2019.

[4] C. Liu, S. Shirowzhan, S. M. E. Sepasgozar, and A. Kaboli, "Evaluation of classical operators and fuzzy logic algorithms for edge detection of panels at exterior cladding of buildings," Buildings, vol. 9, no. 2, p. 40, 2019.

[5] S. Talebi, L. Koskela, P. Tzortzopoulos, M. Kagioglou, and A. Krulikowski, "Deploying geometric dimensioning and tolerancing in construction," Buildings, vol. 10, no. 4, p. 62, 2020.

[6] DIN18203-1997, Tolerances for Building Part1: Prefabricated Ordinary, Reinforced and Prestressed Concrete Components, Deutsches Institut fur Normung E.V. (DIN), Berlin, Germany, 1997.

[7] PCI MNL-116, Manual for Quality Control for Plants and Production of Prefabricated and Prestressed Concrete Products, Prestressed Concrete Institute, Chicago, IL, USA, 2nd edition, 1977.

[8] ACI 117M-06 and ACI Committee 117, Specifications for Tolerances for Concrete Construction and Materials and Commentary.the United States, American Concrete Institute, Farmington Hills, MI, USA, 2006.

[9] GB50204-2015, Code for Quality Acceptance of Concrete Structure Construction, China Architecture \& Building Press, Beijing, China, 2015. 
[10] GB/T51231-2016, Technical Code for Prefabricated, China Architecture \& Building Press, Beijing, China, 2016.

[11] K. Liu, Y. Z. Wang, and G. Liu, "The statistic and analysis of the dimension deviation of cast-in-situ concrete," Construction Technology, vol. 01, no. 1, pp. 98-100, 2008.

[12] W. C. Zhang, "The Research on the Control Indicators of Construction Erection Variation of Prefabricated Concrete Structure," Ph.D. dissertation, North China University of Science and Technology, Tangshan, China, 2019.

[13] Research Group on Reliability of Reinforced Concrete Structural Members, "Investigation and statistical analysis of the dimensional tolerances reinforced concrete structural members," Journal of Building Structures, vol. 6, no. 4, pp. 2-9, 1985.

[14] H. X. Mao and W. Z. Shi, "New methodology of representing the positional error of non-point features in GIS," The International Archives of the Photogrammetry, Remote Sensing and Spatial Information Sciences, vol. 37, pp. 1503-1508, 2008.

[15] M. X. Zhang, "Investigation and study on constructional quality control of concrete structure in Situ," Ph.D. dissertation, Zhejiang University, Hangzhou, Zhejiang, China, 2004.

[16] X. P. Hu, "Investigation and statistical analysis on resistance of building structural members and reliability analysis on residential buildings," Ph.D. dissertation, Xi'an University of Architecture and Technology, Xian, China, 2005.

[17] X. C. Li, "Investigation and statistical analysis on resistance of reinforced concrete structure in Xianyang region," Ph.D. Dissertation, Xi'an University of Architecture and Technology, Xian, China, 2015.

[18] E. F. Acar and L. Sun, "A generalized kruskal-wallis test incorporating group uncertainty with application to genetic association studies," Biometrics, vol. 69, no. 2, pp. 427-435, 2013.

[19] L. D. Ong and P. C. Leclare, "The Kolmogorov-Smirnov test for the log-normality of sample cumulative frequency distributions," Health Physics, vol. 14, no. 4, p. 376, 1968.

[20] A. Ghasemi and S. Zahediasl, "Normality tests for statistical analysis: a guide for non-statisticians," International Journal of Endocrinology and Metabolism, vol. 10, no. 2, pp. 486-489, 2012. 